\title{
Appraising Child Upbringing Values and its Influence on the Psycho-Social Development of Early Adolescents in Buea Sub- Division, South West Region, Cameroon
}

\author{
Tani Emmanuel Lukong. Ph.D.*, Brentford AlemAtemkeng \\ Department of Educational Psychology, Faculty of Education, University of Buea, Cameroon
}

\author{
*Corresponding Author: Tani Emmanuel Lukong. Ph.D., Department of Educational Psychology, \\ Faculty of Education, University of Buea, Cameroon
}

\begin{abstract}
This study examined Child Upbringing Values and its influence on the Psychosocial Development of Early Adolescents in Buea Sub-Division, Cameroon. Child upbringing values considered for this study were morals, tolerance and respect for elders and authority which were examined alongside psychosocial development indicators such as good manners, honesty, respect, positive communication, nurturing and responsive relationship, friendship, competitive greatness, team spirit, industrious and self-control, selfawareness, empathy, poise, loyalty. The objectives for the study were to: Investigate the influence of morals as a cultural value on the development of social skills in early adolescents, to examine the influence of tolerance as a cultural value on the development of emotional competence in early adolescents, to find out the influence of respect of elders and authority as a cultural value on the development of social competence in early adolescents. The study was anchored on Super \&Harkness Developmental Niche Framework. The research design used was cross-sectional survey, the study made use of both quantitative and qualitative data. Data was generated from the administration of 120 closed-ended questionnaire for early adolescents selected randomly in the four locality of the Buea Municipality and two FGD for parents (6 number of mothers and 8 number of fathers). Data collected from the field was subjected to descriptive, exploratory and inferential statistics. However, responses from the closed-ended items were analysed qualitatively and the thematic approach was used for the FGD guide for parents. For descriptive statistics, frequencies and proportions, and Multiple-Response-Analysis (MRS) were used. For inferential statistics, Spearman's Rho Correlation test was used to test the different research questions, while Chi-Square test of Equality of Proportions was used to compare perceptions between male and female early adolescents. Findings showed that Morals as a cultural value does not significantly influenced the psychosocial development of early adolescents $(R=0.150 ; P=0.089)$, Tolerance as a cultural value significantly influence the psychosocial development of early adolescents $(R=0.357 ; P=0.00)$ and Respect for elders and authorities significantly influence the psychosocial development of early adolescents $(R=0.421 ; P=0.00)$. It was therefore recommended that early adolescents should endeavour to have a better understanding of early adolescence as a stage of human development, the psychosocial hallmarks of this stage, together with the numerous developmental issues that can occur if the stage is not properly handled and also be mindful of their activities so as to avoid the repercussions that are associated with this stage of development. Furthermore, early adolescents should understand that they need to internalise the upbringing values their parents are inculcating in them to better their living standards and holistic development. In addition, Laws should be streamlined to prioritise family stability and more specifically parental supervision or care on early adolescents to the economic, material and financial ambitions of families.
\end{abstract}

Keywords: Child Upbringing Values, Psycho-Social Development and Early Adolescents InBuea SubDivision, Cameroon

\section{INTRODUCTION}

Child upbringing in Africa creates a vital fabric of cultural transmission of contextually relevant values, norms etc. Child upbringing has created an interest in almost every discipline in the behavioural sciences. The early experiences of infancy, childhood and early adolescents are assigned a fundamental role in Freudian theories of personality development (Freud, 1930; 1949). This suggests that future behavioural outcomes of early adolescents could be influenced by events experienced in childhood. Naturally then, the role of parents as the primary caregivers and providers of children's upbringing experiences merits further investigation. The child's ability to master and 
exhibit culturally acceptable behaviours forms the basic indication of psychosocial development. Therefore, certain practices are put in place with the aim of providing appropriate child upbringing for child survival, growth, development and wellbeing. Cultural value plays a very important role in child upbringing as well and psychosocial development of early adolescents.

In many African societies' such as Buea communities in Cameroon, child upbringing values influence the psychosocial development of early adolescence through its cultural values, beliefs and norms. Children were taught to respect elders and social hierarchy, sustenance of good friendships, conflict management, caution towards strangers, appreciation of social obligations and responsibilities and above all, to subordinate their individual interests to those of the wider community (Tiberondwa, 1978).Harkness\& Super (1996) maintains that parental values organize daily parenting routines for child and family life. Parents' cultural belief systems channel elements of the larger culture to children. The family plays an enormously important role in child upbringing values, having a significant effect on shaping all spheres of a child's personality when carrying out various everyday activities. The African family is considered to be the primary source of moral values. However, modern families are undergoing transformations as they adapt to an ever-changing world, which brings changes in the family functions, forms and structures as well as the family education model. The amount of time parents spend with their children has been dropping dramatically. As a result, education responsibility has been taken over by institution and other people, which may lead to the deterioration of child upbringing values of children (early adolescents) in the family milieu. This paper therefore, sought to empirically establish the extent to which identified child upbringing values within the context of Buea communities can influence the psycho-social development of early adolescents.

\section{Conceptualising AND Contextualising Issues AND Trends in African Child UPBRINGING DYNAMICS}

Historically children in Africa are highly valued. They are seen as a wonderful blessing from God after marriage, so the care for them is taken seriously. When a woman puts to bed her and the baby goes into confinement, she breasts feeds, carry the child on the back and sleep with the child. It has been observed that taboos against pregnant women eating nutritious foods, delivery in traditional healers' homes, unhygienic care of the umbilical cord, hierarchical or gender biased food distribution have a debilitating effect on the mother and the baby's health (Onigbodun \&Olatawura, 2008).

Human beings do not grow up, and adults do not parent, in isolation, but in multiple contexts (Bornstein, 2002; Bronfenbrenner, 1999; Lerner, Rothbaum, Boulos, \&Castellino, 2002). Child upbringing practices of one's own culture seem "natural," but some practices may actually be rather unusual in an absolute sense. Families take different forms; nuclear families represent only one of a variety of distinct social ecologies in which we find parents. Children in many cultures are tended to by a variety of non-parental care providers, whether in family day care, day care centres, villages, or fields. Situations like day care represent one of the ways in which people outside the family "parent" children in meaningful ways. Furthermore, most nations in the world are characterized by social heterogeneity; ethnic differences within countries equally colour child upbringing beliefs and practices.

Cameroon being a patriarchal society, men enjoy hegemony over decision making on important issues, like the care of children. In the extended family system, close ties exist between men (husbands) and their parents as well as other relatives such that men, in conjunction with their parents, take most family decisions (Babalola, 1991). As observed by Orubuloye (1995) "in much of African society, the great majority of people still live in extended families either with or in close proximity to relatives". This facilitates stronger influence of relatives on the life and decision of husbands.

The way a child is brought-up greatly influences the child's development mentally, socially, emotionally, physically and morally. However in recent times, educational institutions such as Nursery \& Day care centres have taken over the responsibility of child upbringing in Cameroon and beyond. Judging from the ways and manners Cameroonians handle their children, it appears we are still in the dark ages when children were accepted to be born sinful and evil and needed to be exorcised through punishment or that they are miniature adult that has to carry out our instructions and be moulded into the image we carve out for them. This may be the reason behind our violence 
attitude to children accusing them of witcheraft and wizardry. Some of Africa's child up bringing practices could be categorized as child abuse (Idogo, 2001).

LeVine's (2004) maintains that child development and the "quality" of early adolescent's care and services inspired by and framed within the dominant mainstream narratives generally pathologies' African forms of child upbringing and child guidance. In the same line LeVine's says Research in Africa revealed that African reproductive ideologies and parenting practices were built on "alternative patterns of care based on different moral and practical considerations" that constituted "normal patterns of development that had not been imagined in developmental theories."

Similarly, Zeitlin (1996) explained how the feeding habits of African parents that non-Africans regard as counterproductive are useful. By contrast, Weisner, Math- eson, and Bernheimer (1996) thought that American parental beliefs on the importance of early "stimulation" for optimal child development could lead to an unnecessary concern about the earliest possible interventions for children with developmental delays. Serpell (1994) concluded from a review of Human development in cultural context: a third world perspective (Nsamenang, 1992b) that it espoused a theory of the universe that diverges from that which informs contemporary Western developmental science.

Thus, the huge diversity in parenting practices results in differentiation in desirable child outcomes. Moreover, Africa's sociogenic developmental trajectory "differs in theoretical focus from the more individualistic accounts by Freud, Erikson, \& Piaget" (Serpell, 1994). Ngaujah (2003) felt that Africa's peculiar theories and the developmental processes and practices that follow from them cogently posit the impetus to look at Africa from a different perspective in the field of psychology and human development. The most appropriate framework would be a learning posture (Agar, 1986) framed by the scientific method, as a generic approach that could "discover" new methodologies, new ways of understanding, and new concepts about development and situated intelligences, for example, in any culture and context.

Nsamenang (2008) carried out a study on dilemmas of right-based approaches to child wellbeing in an African cultural context. The title of this recent book on early adolescence development book as acknowledged by Garcia, Pence, \& Evans (2008), captures the Africa's Children, Africa's challenge interest and concern for Africa's difficulties with its huge child populations. The child and adolescent cohorts exceed $60 \%$ in many African countries (Nsamenang, 2002). Fourteen of the eighteen countries in the world whose population of children ages $0-14$ years is $45 \%$ or more are African (CIA, 2007). About $20 \%$ of sub-Saharan Africa's total population of children below 6 years of age is seriously at risk. Parental values organize daily parenting routines for child and family life (Harkness\& Super, 1996). Parents' cultural belief systems channel elements of the larger culture to children.

Accordingly, children in Africa is best visualized within an African theory of the universe, which envisions a circular path to human ontogenesis in three phases, identifiable more by cultural imperatives than by the biological markers that trigger them (Nsamenang, 2008). Social selfhood is an experiential reality, the physically existing human being that begins with conception and connects the two metaphysical phases of spiritual and ancestral selfhood (Nsamenang, 1992, 2005). The existential self or social selfhood, the primary subject content of developmental science, develops through seven stages namely, pre-birth/neonatal, social priming, social apprenticing, social entrée, social internment, adulthood, and old age/death (Nsamenang, 1992).An African theory draws from life journeys in African cultural settings (Serpell, 1993) to recognize the transformation of the human new-born from a biological entity into a viable cultural agent of a particular community en route to adulthood.

As children develop, they gradually and systematically enter into and assume different levels of personhood, identity, and being (Nsamenang, 2005). Children are not born with the knowledge and cognitive skills with which to make sense of and to engage the world; they learn or grow into them as they develop (Nsamenang, 2004). Based on perceived child states and milestones of human ontogenesis, Africans assign sequential cultural tasks to the stages of development they recognize. In this way, they organize child development as a sociogenic process, with cultural beliefs and practices that guide systematic socialization, education, and the expectations required for each ontogenetic stage.

Accordingly, we can interpret child development as the acquisition and growth of competencies in the physical, cognitive, social, and emotional domains and the moral maturity required to competently 
engage in the world, implying the family, community, and the society at large. Children learn the 'proper' ways to relate to parents and other kin, when and how to express emotion, moral behaviour, obedience, honesty tolerance and also what counts as intelligent behaviour (LeVine et al., 1994). Hierarchical patterns, in which children occupy subordinate positions to adults, are taught from a very young age.

All societies use the notion of intelligence to refer to children who can solve problems and often children are regarded as intelligent if they are helpful (Serpell, 1993). However, the problems that children are required to solve may differ across contexts, particularly between those that have embraced and live in a modern world and those who live a rural or more traditional life. In a modern community, a young child who can complete a pattern matching task more rapidly than peers as well as portrays features of child upbringing values like respect for elders, honesty, tolerance and compassion would be regarded as showing intelligence and in the long run making him acquire social and emotional competence. Bringing up a child is a complex process the aim of which is to trigger some defined and permanent changes in its personality. It has to equip the child with knowledge, skills, attitudes and beliefs which enable the child to develop and properly function in the social environment later on. That is why a commonly accepted system of values, being the foundation of social norms and rules (Okoń, 2007) should constitute a basis of these activities.

According to Mariański (2006), the values, norms and assessments, derived from the conceptions of perceiving good and evil, which regulate relations between members of a definite society, should be understood as an individual's morality. In the author's opinion, the components of these are goals, norms and moral appraisals as well as patterns of behaviours and sanctions. Therefore, moral upbringing is the process of introducing the child to the world of values and moral norms. It is about a mutual influence of a tutor (teacher) and the child in order to shape the child's specific psychical predispositions, being the foundation of attitudes and moral behaviours of an individual. For the process to be effective, the specific goals should be pursued in a planned, well thought out and systematic way. Beginning from the earliest years of the child's life, the right values, views and attitudes should be emphasized, and various methods, forms and means of influence should be considered in other to build his social skills as well as his social and emotional competences. It is important to adjust the activities to the developmental possibilities of the child, its cognitive skills, the level of emotional and social development as well as its abilities to moral reasoning (Okoń, 2007). This goes a long way to help build the child self-esteem, honesty as a high sense of moral value and great sense of empathy.

The older generation is like a treasury of life knowledge and interpersonal relationships for their grandchildren. Grandmothers and grandfathers, who draw on their own experiences and reflections, and are aware of own educative mistakes, are predisposed to become some kind of a teacher of the world. They are prepared to teach their grandchildren how to perceive others' needs, respect or tolerance and compassion. They can teach them values which they see from the angle of their own life experiences as valuable, they can shape the younger generation's moral attitude (Czaszdziecmi.pl, 2016). A close contact with grandparents may have an essential influence on building the child's world of values and shaping its moral attitudes. That is why from the perspective of the child's education, it is important for the parents or caregivers of children to always have as frequent contacts with the older family members like grandparents and great grandparents as it is possible.

Upbringing in the family takes place in an intended way through intentional, planned educational activities (reflexive education), and in an unintended way, in the course of everyday activities, accidental conversations or spontaneous behaviours in certain situations (unreflexive education). Education gained by the child in such situations facilitates acquiring new social skills as well as emotional and social competences in order to express own beliefs and views regarding the surrounding reality and interpersonal relations. Values, norms and rules found in the family environment decide about the way the young generation (child) enters the adult life and its normal functioning in the society.

Child upbringing values like respect for elders, tolerance, honesty and morals are a key element of the child's personality development. That is why shaping normal attitudes and behaviours towards the world, other people and oneself, becomes the most important aspect of the family education (Lukong, 
2018). Transformations of the modern family, economically and socially conditioned, limit the opportunities of a proper and full educational influence on the young generation. Drifting apart of its members from one another, focusing on self-realization and delegating educational duties to others strangers may significantly limit the educative efficiency as well as values of the family environment. Lack of right role models in the nearest environment will simply have a negative impact on the child psychosocial development as the child generally depends on the tutors for change. Weak bonds with the family may lead children to emotional instability and moral confusion. That, in turn, may result in dangerous activities, self-destruction, aggression and brutal behaviours.

Family is a part of a social and cultural surrounding that plays an essential role in shaping the child's personality (Szczepański, 1993). Its educative function is mainly to introduce the child to the widely understood social and cultural life together with rules, values and moral standards related to it (Adamski, 1984). In order to fulfil that function, the family has to meet the basic biological and psychical needs of the child, the need to be loved, feel safe, appreciated and accepted. It should also provide the child with socially required patterns of behaviour and emphasize values, norms and rules of coexistence typical in the society.

Parents are the first role models of moral behaviours for children. The process of their personal development takes place in the atmosphere of norms, rules and moral principles which are followed in the family. The child observes what is going in the family environment and follows certain patterns of behaviour. Thus, it can be stated that the moral system of the child is shaped through observation and imitation of conducts which were presented to the child in the course of a family upbringing in which the process of personality shaping takes place during various life activities. This is education through participation in everyday life situations, connected with both economic sphere as well as cultural and social life of the family (Langier, 2012).

Educative activities of a modern family are more seldom focused on the emotional, social and moral sphere of children. They are mainly based on shaping competences enabling the child to act efficiently in order to achieve successes in certain fields in a fast way. According to Anna Kwak (2005) a modern family is a basis preparing a young generation for independent life it helps to gain education, supports individual development of a person taking into consideration the person's talents, needs and interests. In the modern family material goods, family traditions or moral values are not traditionally handed down from generation to generation.

Early adolescence is a very critical period and stage of an individual life span. Modern generation of African children today are exposed to a whole lot of knowledge and information as some African family and parents are gradually inculcating the Caucasians values into their children to the expense of our indigenous African values. In the Buea municipality of the southwest region of Cameroon, Parents share the motivation to care for their children so that their offspring can develop social skills as well as social and emotional competencies to master life on its own. However, parents remarkably differ in their views of what these competencies are and how they can be promoted in child upbringing. These differences can be regarded as representing the imprint of their respective cultural contexts. Research has demonstrated that culture specificity of parenting ideas and practices is based on different cultural models, incorporating diverging values and norms. As a consequence, parenting strategies can vary remarkably. Within eco-cultural models of parenting, child upbringing values and practices are adapted to the prevalent cultural context (Keller, 2007; Super \&Harkness, 1986; Whiting, 1963). Each cultural context therefore provides the framework within which child upbringing values takes place.

Theoretically, this study was anchored on the idea of developmental niche, Super \&Harkness with a framework for thinking about human development in cultural context (Super \&Harkness, 1986). It can be used to organize information about children's development and to focus investigations for improving the lives of children and families. Although it is not a theory of development in the formal sense, the developmental niche provides a framework for understanding how cultures guide the process of development. By using this framework, it is possible to see how the cultural environments of particular children are organized to see how the culture is presented to the child through its values at any particular time. 


\section{THEORETICAL FRAMEWORK FOR THE STUDY}

\subsection{The Developmental Niche Framework (Super \&Harkness, 1986)}

The idea of the developmental niche suggest a framework for thinking human development in cultural context (Super \&Harkness, 1986). It can be used to organize information about children's development and to focus investigations for improving the lives of children and families. Although it is not a theory of development in the formal sense, the developmental niche provides a framework for understanding how cultures guide the process of development. By using this framework, it is possible to see how the cultural environments of particular children are organized to see how the culture is presented to the child through its values at any particular time.

The term niche is borrowed from biological ecology, where it is used to describe the combination of features of the environment a particular animal, or a species of animal, inhabits. Thus a pigeon and a robin might live "in the same place" in the sense of dwelling in the same part of a city park. But exactly where they build their nests and from what materials, the kind of food they seek in the surrounding environment, their vulnerability to various predators, all these are distinct. The particular way they fit into and exploit the same general environment is different, and they thus create a distinct niche for themselves. At the centre of the developmental niche, therefore, is a particular child, of a certain sex and age, with certain temperamental and psychological dispositions. By virtue of these and other characteristics, this child will inhabit a different cultural world than the worlds inhabited by other members of his family and further, the child's world will also change as the child grows and changes.

There are three major aspects of this child's culture that shape his or her life. These three components together make up the developmental niche. The first component is the physical and social settings of everyday life. This includes such basic facts of social life as what kind of company the child keeps. In rural Kenya, for example, families are large mothers often have eight or more children and with the activities of these people based mainly at home, the baby or young child is likely to have several playmates and caretakers who are siblings. The size and shape of the living space is also an important feature of physical and social settings.

By contrast, in the southern part of Holland where many people live in a small geographic area, house are very compact and the living room also serves as the children's playroom. Typically, if there is a baby or toddler in the house, there will be a playpen located in this room, where he or she can play independently with toys while yet in close proximity to other members of the family. Even aspects of life as basic as sleeping and eating schedules are organized by the physical and social settings of daily life. While Kenyan babies sleep with their mothers and wake to nurse at intervals through the night, for example, Dutch children are put to bed rather early by U.S. standards and learn to stay there until it's time to get up. In contrast, young children in Italy and Spain are often kept up until late at night in order to participate in family and community events.

One cannot get very far in studying the physical and social settings of children in different cultures without realizing that many aspects of children's environments are organized by customary practices; and it is for this reason that we identify customs of child care and child rearing as the second component of the developmental niche. The use of older siblings as caretakers in rural Kenya, for example, is customary. There are special terms for these child nurses in the native languages of Kenya, and they are expected to care for their young charges in a special way that is different from mothers' care. Likewise, the use of playpens in Holland is customary; it is a commonly accepted solution for the problem of how to keep babies and toddlers safe and happy in the Dutch living environment. And both bedtimes and sleeping arrangements for infants also tend to follow customary patterns in different communities. This fact points to an important aspect of customs as they are normative for families and communities. Very often, in fact, customs of care are seen by their users as the only reasonable solution to whatever need they address, indeed, the natural way to do things.

Customs of care are thus a source of support for parents and other caretakers because they provide ready-made solutions to the myriads of issues that developing children present, from how to protect children from hazards in the environment to how to ensure that they are adequately educated for their future roles in society. But sometimes the function of a custom is less easy to specify because its value is primarily symbolic. Why do North American Jews and most Christians circumcise their infant sons? Why are Japanese children taught just the right brush strokes to write the pictographs of the 
Japanese alphabet? Why do many Native American adolescents embark on a solitary spirit quest? To understand these customs of child care and child upbringing, one needs to take into account cultural traditions related to spirituality and concepts of the person. Although these abstract dimensions of culture are difficult to describe, the study of customs which represent them can provide insights into the cultural ways of thinking that organize the lives of families and children.

It is these cultural ways of thinking and feeling, held by parents and other caretakers that we recognize as the third component of the developmental niche, the psychology of the caretakers. Parents' cultural belief systems and related emotions underlie the customs of child upbringing and validate the organization of physical and social settings of life for children. In cultures where babies and young children customarily sleep close to their parents, for example, parents often feel that to put the child elsewhere even worse, to fail to attend to a child who wakes crying in the night amounts to no less than neglect.

On the contrary, among U.S. middle class families where babies are often put to bed in their own separate rooms, practices geared to teaching the baby to sleep through the night and quiet itself upon waking are understood as part of a larger agenda to train the child to be independent, a culturally important attribute throughout life. We can see in this case that parental beliefs about sleeping arrangements in both kinds of settings reflect more general ideas about the person in society. The psychology of the caretakers, thus, is an important channel for communicating general cultural belief systems to children, through very specific context based customs and settings.

The diagram below illustrates these three components of the developmental niche and their relationships to each other, the child, and the wider environment. First, the settings, customs, and caretaker psychology, as explained above, form the immediate micro-environment of the child: they are the developmental niche.

The three double-headed arrows represent an important relationship within the niche, that is, that the three components influence each other. A variety of forces, psychological and practical, promote a sense of harmony among the three components. Parents do not easily leave their children in settings which they judge to be dangerous. The customs of child care are generally adapted to the particular physical and social settings, as well as to what are symbolically acceptable to the caretakers. A steady state of complete harmony is rarely achieved, but as the irregular lines separating the components suggest, the points of contact are somewhat flexible. In this sense, the niche operates as a system, the semi-independent parts constantly influencing and adapting to each other.

The larger, single-headed arrows illustrate a second dynamic of the niche, namely that various aspects of the larger human ecology differentially influence the three components of the niche. The customs carry a particular weight of history and are a conservative force such that, other things being equal, many parents will, "without thinking," rears their children with many of the same traditions they grew up with. Economic and demographic changes may rapidly affect the settings of daily life for children. They may spend their day with fewer brothers and sisters, in a day care centre, or in an urban environment. The psychology of the caretakers may be directly influenced by shifting ideas at the national or community level about the nature of children and their needs, as well as about what skills they will need for the future. In summary, there are many ways that changes in the larger society or physical environment can influence the child, but they do not all operate through the same components of the niche.

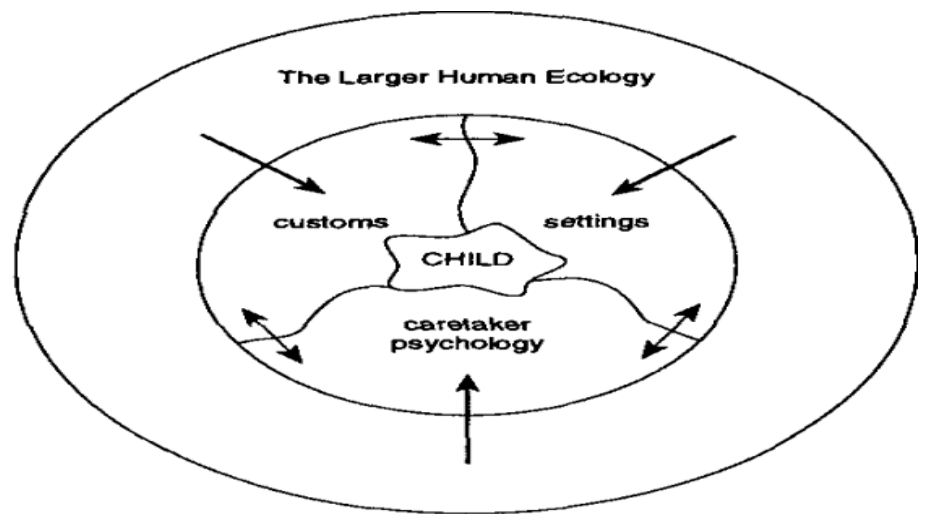

Figure1. A Schematic Representation of the Developmental Niche 
Finally, the developmental niche formulation recognizes the fact that the child and its environment accommodate each other: in the diagram below, their curves are mutually adjusted. Some views of child development emphasize the way child behaviour is shaped by the environment, that is, the degree to which children must adapt to the requirements of their family and their culture. But it is also true, as more recent research has shown that parents and caretakers alter their demands and their supports in response to the particular temperament and talents of the individual child. In addition, the child is a rapidly changing person, especially in the early years. Language and social skills develop, personal interests emerge, and the child learns to cope with, or avoid, specific features of the niche. The niche, in this sense, also develops in response to the changing child, as well as to the outer influences. Of course many features remain constant, or at least present challenges that grow in a way parallel to changes in the child. These are the themes that take on particular strength as the child matures, themes that are most deeply woven into the values, motives, and fears of the emerging adult.

The cultural experiences of children are able to play such an important and lasting role in shaping the thoughts, feelings, and behaviour of people throughout their lives. The theoretical framework of the developmental niche helps to achieve such an understanding through systematic analysis of the culturally constituted components of the child's environment and their relationships with each other, the wider environment, and the child. In this analysis, it is clear that the cultural environment of the child is powerful not only because it is experienced during the formative years of life, but also because it constitutes an interactive system in which the same cultural messages are conveyed through a variety of modalities. Just as in language where the same idea may be communicated through choice of words, grammatical structure and tone of voice, so in cultural environments the child may learn the same ways of thinking and acting through the physical and social settings of daily life, the customs in which he or she participates, and the expressions of parents' ideas that are conveyed in a variety of ways. Over the span of development, these messages become so internalized that they form the core of our understandings of the world and us. It is in this sense that ethos and psyche-culture and individual psychology are fused in the re-creation and transformation of culture within the individual mind.

This theory is relevant to the influence of child upbringing values and psychosocial development of early adolescents because, it explains how the cultural context in which the children dwell in impinge on their upbringing values as well as how some three basic components (customs, caretaker psychology, setting and the larger human ecology) shape children development.

\subsection{Statement of the Problem}

There exists a vast body of literature that emphasizes the relevance of child upbringing values and "psychosocial development of early adolescents. This interest stems from the idea that parents are primarily responsible for nurturing or "bending" their children in the right direction, carefully grooming them from "twig" to "tree" or into an early adolescent that possesses desirable traits and values as deemed appropriate by society (Maccoby, 2000). The ways through which this can be achieved include supervision, teaching and disciplining during the process of child upbringing as early adolescents is a time where children are considered to be still "plastic" in nature. The underlying notion here then is that parents exert a powerful impact on the personality characteristics that early adolescent develop and influences the direction they take in their lives.

Among the factors related to early adolescent's psychosocial development, child upbringing values continue to generate much attention. From the researcher's observations, the inhabitants of the locality of Mokunda, Bokwango, Small Soppo, Wunganga and Bonduma make a greater part of the population. There is a lot of upbringing values that pre-adolescents exhibit, some of this values include respect for elders and traditional authority, communication skills, etiquette, morals, honesty and tolerance though are in a rattle with the coming of the information communication technology (ICT) like television, internet, Face book where children are widely exposed to the world, which makes them to internalize western values as well as turn to internalize weak bonds with the family which leads children to emotional instability and moral confusion. This incongruity and conflicting socialization of values in turn, results in treacherous activities such as self-destruction, aggression and brutal behaviours as well as anti-values like immorality, disrespect for elders and traditional authority, bad manners and a figurative way of speaking. This conflicts with the existing cultural child upbringing values like respect for elders and authority, morality, etiquette, communication skills, 
good mannerism, a sense of empathy plus tolerance as well as the sense of being compassionate which helps to mould their social skills (cooperation, respect, honesty, accepting differences, selfsatisfaction and positive communication skills), equally it erect their socio emotional competences in other for this early adolescents to be better adults with exonerating personalities.

Equally a major increase in the number of nonstandard behaviours with regards to the Bakweri child upbringing portrayed by early adolescents like depression, anxiety, sexual abuse, violence, juvenile delinquencies, teenage pregnancy and the poor personality profile from these localities of Mukunda, Bokwango, Small Soppo Wunganga and Bonduma could be traced right back to their childhood, due to the neglect of parents, family, caregivers, community and leaders to inculcate in them or to create a conducive environment that enhances an appropriate efficient child upbringing values for a good personality profile and psychosocial development. The problematic here is based on the conflicting natures of early adolescent's inability to learn and exhibit culturally acceptable values that is why the researcher deemed it relevant to investigate the phenomenon.

\subsection{Objectives of the Study}

Specifically, the study sought to:

- Investigate the influence of morals as a cultural value on the development of social skills in early adolescents.

- Examine the influence of tolerance as a cultural value on the development of emotional competence in early adolescents.

- Examine the influence of respect for elders and authority as a cultural value on the development of social competence in early adolescents.

\section{RESEARCH METHODS}

A cross-sectional survey research design was adopted for the study. A cross-sectional survey research design is one in which a group of persons or items is studied by collecting and analysing data from a portion of the population, considered to be representative of the parent population to describe a present situation. The cross-sectional research was chosen because it has the advantage of providing a large amount of valuable data in a very short timeframe. The cross-sectional nature of the study specifically, is explained by the fact that the study is aimed at describing the current situation (giving a snapshot of the current contextual reality) without any follow up. Furthermore, the design was applicable because the study involved collecting the opinions of people (parents and children) in relation to the variables under study by the use of questionnaires. Additionally, only a part of the population (sample) was studied and its findings were expected to be generalized to the parent population.

Out of the 58 villages that made up the Buea municipality 4 of its most populated villages where taken into cognizance, that is Mokunda, Bokwango, Small SoppoWunganga and Bonduma. Sample size was estimated using sample calculation for one proportion with the support of EpiInfo 6.04d (CDC, 2001). The population for this study was purposively selected with the view that they could provide relevant information in relation to the research question.

Communities were sampled using simple random sampling whereby 4 communities were sampled, 2 from the rural area and another two from the urban area. The criteria for distinguishing the rural area from the urban area was due to the fact that, the rural area refers to the villages and hamlet, which have less rate of urbanization and industrialization. The major source of earning in the rural area is through agriculture as not much employment opportunities are available. Even though nowadays, rural settlements are near the boundaries of the cities which make the people's access to medication and education quite easy. Whereas urban areas refers to the area with elite or top class facilities available as compared to the rural areas. In this type of area, the rate of industrialization and urbanization is quite high. Persons in the urban area earn their leaving through service jobs and industrialization. The sampled communities were as presented on the table below. 
Appraising Child Upbringing Values and its Influence on the Psycho-Social Development of Early Adolescents in Buea Sub-Division, South West Region, Cameroon

Table1. Representation of sample by localities

\begin{tabular}{|l|l|l|l|l|l|}
\hline Community & Population & $\begin{array}{l}\text { Estimated population } \\
\text { of children aged 9 to } \\
\mathbf{1 4} \text { to }\end{array}$ & Sample size & $\begin{array}{l}\text { Minimum } \\
\text { expected }\end{array}$ & \% \\
\hline Bokwango & 1,721 & 224 & 46 & 37 & 11 \\
\hline Mokunda & 1,400 & 182 & 38 & 30 & 9 \\
\hline Bonduma & 6,000 & 780 & 161 & 129 & 40 \\
\hline Small soppowunganga & 6,000 & 780 & 161 & 129 & 40 \\
\hline Total & $\mathbf{1 5 , 1 2 1}$ & $\mathbf{1 9 6 6}$ & 407 & 326 & 100 \\
\hline
\end{tabular}

This sample size was shared equally between male and female children.

\subsection{Findings of the Study}

Table2. Morals as a cultural value and the psychosocial development of early adolescents

\begin{tabular}{|l|l|l|}
\hline \multirow{4}{*}{ Moral values } & Spearman's rho & Psychological development \\
\cline { 2 - 3 } & Correlation Coefficient & .150 \\
\cline { 2 - 3 } & Sig. (2-tailed) & .089 \\
\cline { 2 - 3 } & $\mathrm{N}$ & 130 \\
\hline
\end{tabular}

Table 2 above indicates that; morals as a cultural value does not significantly influence the psychosocial development of early adolescents $(\mathrm{R}=0.150 ; \mathrm{P}=0.089)$. The positive sign of the correlation coefficient implies that, the better the early adolescents are inculcated with good moral values, the better their psychosocial development.

Table3. Tolerance as a cultural value and the psychosocial development of early adolescents

\begin{tabular}{|l|l|l|}
\hline \multirow{3}{*}{ Tolerance values } & Spearman's rho & Psychological development \\
\cline { 2 - 3 } & Correlation Coefficient & $.357^{* * *}$ \\
\cline { 2 - 3 } & Sig. (2-tailed) & .000 \\
\cline { 2 - 3 } & $\mathrm{N}$ & 130 \\
\hline
\end{tabular}

**. Correlation is significant at the 0.01 level (2-tailed).

Table 3 indicates that, tolerance as a cultural value significantly influence the psychosocial development of early adolescents $(\mathrm{R}=0.357 ; \mathrm{P}=0.00)$. The positive sign of the correlation coefficient implies that the better early adolescents are educated to be tolerant, the better their psychosocial development.

Table4. Respect for elders as a cultural value and the psychosocial development of early adolescents

\begin{tabular}{|l|l|l|}
\hline & Spearman's rho & Psychological development \\
\hline \multirow{3}{*}{ Respect for elders and authorities } & Correlation Coefficient & $0.421^{* * *}$ \\
\cline { 2 - 3 } & Sig. (2-tailed) & .000 \\
\cline { 2 - 3 } & $\mathrm{N}$ & 130 \\
\hline
\end{tabular}

**. Correlation is significant at the 0.01 level (2-tailed).

Respect for elders and authorities significantly influence the psychosocial development of early adolescents $(\mathrm{R}=0.421 ; \mathrm{P}=0.00)$. The positive sign of the correlation coefficient implies that the better early adolescents are educated to respect elders and authorities, the better their psychosocial development.

Table5. Psychosocial development of Early Adolescents

\begin{tabular}{|l|l|l|l|l|l|l|}
\hline Item & \multicolumn{2}{l|}{ Stretched } & \multicolumn{2}{l|}{ Collapsed } \\
\cline { 2 - 7 } & $\begin{array}{l}\text { Strongly } \\
\text { disagree }\end{array}$ & Disagree & Agree & $\begin{array}{l}\text { Strongly } \\
\text { agree }\end{array}$ & $\begin{array}{l}\text { SD } \\
\text { D }\end{array}$ & A \&A \\
\hline $\begin{array}{l}\text { I know that it is good to respect } \\
\text { elders. }\end{array}$ & $\begin{array}{l}10.8 \% \\
(14)\end{array}$ & $\begin{array}{l}16.2 \% \\
(21)\end{array}$ & $\begin{array}{l}30.8 \% \\
(40)\end{array}$ & $\begin{array}{l}42.3 \% \\
(55)\end{array}$ & $\begin{array}{l}26.9 \% \\
(35)\end{array}$ & $\begin{array}{l}73.1 \% \\
(95)\end{array}$ \\
\hline It is not good to be greedy. & $\begin{array}{l}10.8 \% \\
(14)\end{array}$ & $\begin{array}{l}14.6 \% \\
(19)\end{array}$ & $\begin{array}{l}36.2 \% \\
(47)\end{array}$ & $\begin{array}{l}38.5 \% \\
(50)\end{array}$ & $\begin{array}{l}25.4 \% \\
(33)\end{array}$ & $\begin{array}{l}74.6 \% \\
(97)\end{array}$ \\
\hline $\begin{array}{l}\text { I should be wicked or harsh with } \\
\text { others. }\end{array}$ & $\begin{array}{l}23.1 \% \\
(30)\end{array}$ & $\begin{array}{l}20.0 \% \\
(26)\end{array}$ & $\begin{array}{l}30.8 \% \\
(40)\end{array}$ & $\begin{array}{l}26.2 \% \\
(38)\end{array}$ & $\begin{array}{l}43.1 \% \\
(56)\end{array}$ & $\begin{array}{l}56.9 \% \\
(74)\end{array}$ \\
\hline
\end{tabular}


Appraising Child Upbringing Values and its Influence on the Psycho-Social Development of Early Adolescents in Buea Sub-Division, South West Region, Cameroon

\begin{tabular}{|l|l|l|l|l|l|l|}
\hline \multicolumn{9}{|l}{} \\
\hline I should put eyes on people things. & $\begin{array}{l}23.8 \% \\
(31)\end{array}$ & $\begin{array}{l}25.4 \% \\
(33)\end{array}$ & $\begin{array}{l}29.2 \% \\
(38)\end{array}$ & $\begin{array}{l}21.5 \% \\
(28)\end{array}$ & $\begin{array}{l}49.2 \% \\
(64)\end{array}$ & $\begin{array}{l}50.8 \% \\
(66)\end{array}$ \\
\hline $\begin{array}{l}\text { I help my friends when they are in } \\
\text { need. }\end{array}$ & $\begin{array}{l}8.5 \% \\
(11)\end{array}$ & $\begin{array}{l}14.6 \% \\
(19)\end{array}$ & $\begin{array}{l}43.1 \% \\
(56)\end{array}$ & $\begin{array}{l}33.8 \% \\
(44)\end{array}$ & $\begin{array}{l}23.1 \% \\
(30)\end{array}$ & $\begin{array}{l}76.9 \% \\
(100)\end{array}$ \\
\hline I envy my friends and neighbours. & $11.5 \%$ & $14.6 \%$ & $44.6 \%$ & $29.2 \%$ & $26.2 \%$ & $73.8 \%$ \\
& $(15)$ & $(19)$ & $(58)$ & $(38)$ & $(34)$ & $(96)$ \\
\hline $\begin{array}{l}\text { I speak figuratively to my parents, } \\
\text { friends, elders and neighbours. }\end{array}$ & $12.3 \%$ & $17.7 \%$ & $40.8 \%$ & $29.2 \%$ & $30.0 \%$ & $70.0 \%$ \\
$(16)$ & $(23)$ & $(53)$ & $(38)$ & $(39)$ & $(91)$ \\
\hline I do cooperate with my friends and & $6.9 \%$ & $13.1 \%$ & $26.2 \%$ & $53.8 \%$ & $20.0 \%$ & $80.0 \%$ \\
neighbours. & $(9)$ & $(17)$ & $(34)$ & $(70)$ & $(26)$ & $(104)$ \\
\hline MRS & $13.5 \%$ & $17.0 \%$ & $35.2 \%$ & $34.3 \%$ & $30.5 \%$ & $69.5 \%$ \\
& $(140)$ & $(177)$ & $(366)$ & $(357)$ & $(317)$ & $(723)$ \\
\hline
\end{tabular}

$\mathrm{N}_{\text {cases }}=130 ; \mathrm{N}_{\text {responses }}=1040$

Early adolescents were generally satisfactory of their psychosocial development (69.5\%) whereby $34.3 \%$ were actually convinced of their psychosocial development.

They mostly perceived that they do cooperate with friends and neighbours with a proportion of $80.0 \%$ (104). This was followed by "I help my friends when they are in need" with a proportion of $76.9 \%$ (100). Those that stipulated that "it is not good to be greedy" were $74.6 \%$ (97) whereby $38.5 \%$ (50) were actually persuaded. Equally $73.8 \%$ (96) stated "I envy my neighbours and friends" whereby 29.2\% (38) actually ascertained. $73.1 \%$ (95) perceived "I know that it is good to respect elders" whereby $42.3 \%$ (55) actually concur. A proportion of $70.0 \%$ (91) concur "I speak figuratively to my parents, friends, elders and neighbours". Then 56.9\% (74) said I should be wicked or harsh with others whereby $26.2 \%$ (38) actually ascertained. Lastly those who put their eyes on people things were $50.8 \%$ (66) whereby $21.5 \%$ (28) were actually persuaded.

\subsection{Educational Implications of the Study}

This study would help educators and teachers to tremendously understand and appreciate why learners behave in a particular manner or portray certain behaviours in a classroom situation. Once armed with appropriate child upbringing values such morals, tolerance, respect for elders and authority and honesty, teaching and learning will be very interesting as educators are going to understand their learners in their diverse child upbringing values.

It is cardinal as teachers and educators in general to have knowledge of child upbringing values and how it impacts on the educational system of Cameroon. This study seeks to establish a platform were educators and teachers could use as a guide to help shape their thinking as well shape the behaviours of learners who try to portray in appropriate child upbringing values such as disrespect and dishonesty in school toward their peers.

In addition, due to our diverse characteristics and nature as human beings, we are bound to have different learners from diverse cultural backgrounds and child upbringing values. The researcher in this study seeks to enlighten educators and teachers on how to go about the various behaviours portrayed by learners in their various classrooms, as it creates and awareness to educators and teachers that once a learner portray a behaviour which is not socially acceptable by the school or institution it could be traced from the child upbringing values the learner had internalise in his/her early stages of life and so their duty is to help curb or eradicate that in appropriate child upbringing behaviour put forward by the learner rather than insulting him/her.

This study through its independent variables (morals, tolerance, respect for elders and authority) advocates for the teaching of value-based education in our curriculum. The study of morals and ethical values which are all child upbringing values that makes us a perfect person is equally valuebased education. Advocates of value based education argue that educating learners about child upbringing values and values at large is more important than just teaching them algebra, biology or even literature. Mahatma Gandhi once said that "education not only moulds the new generation but also reflects a society's fundamental assumptions about itself and the individuals that composed it". The primary reason for this may be based on the argument that a normal educational course has three processes: (1) providing general and specific information and knowledge, (2) teaching skills, and (3) inculcating values. But today's education is geared mainly to the first process, with little emphasis on 
the second and very minimal emphasis on the third. Though some remarkable changes are being felt in higher institution of learning with the teaching of civics and ethics in our universities but yet a greater deal is still to be done.

\section{RECOMMENDATIONS}

It is suggested that early adolescents should have a better understanding of early adolescence as a stage of human development, the psychosocial hallmarks of this stage, together with the numerous developmental issues that can occur if the stage is not properly handled. They should also be mindful of their activities so as to avoid the repercussions that are associated with this stage of development. Furthermore, early adolescents should understand that they need to internalise the child upbringing values their parents are inculcating in them to better their living standards and holistic development.

Equally, child upbringing values should be introduced in our school's curriculum, from the primary right up to the higher education through a value-based education. This is to make sure that our learners grow up to be responsible citizens in the society.

Laws should be streamlined to prioritise family stability and more specifically parental supervision or care on early adolescents to the economic, material and financial ambitions of families, the State should bear in mind that these early adolescents are the future leaders of tomorrow and their proper development is imperative if they are to become socially and morally acceptable members of society.

\section{CONCLUSION}

Based on the findings obtained from this study, and with regards to the study problem, it was discovered from the variables under study that child up bringing values influenced the psychosocial development of early adolescents both positively and negatively as demonstrated on the conceptual diagram and till measures are being taken to improve on child upbringing values, it still remain a societal malaise as cultural values moulds parents' beliefs about parenting practice, behaviour management, discipline and control. This study through its independent variables (morals, tolerance, respect for elders and authority) advocates for the teaching of value-based education in our curriculum.

The study of morals and ethical values which are all child upbringing values that makes us a perfect person is equally value-based education. Advocates of value based education argue that educating learners about child upbringing values and values at large is more important than just teaching them algebra, biology or even literature. Mahatma Gandhi once said that "education not only moulds the new generation but also reflects a society's fundamental assumptions about itself and the individuals that composed it". The primary reason for this may be based on the argument that a normal educational course has three processes: (1) providing general and specific information and knowledge, (2) teaching skills, and (3) inculcating values. But today's education is geared mainly to the first process, with little emphasis on the second and very minimal emphasis on the third. Though some remarkable changes are being felt in higher institution of learning with the teaching of civics and ethics in our universities but yet a greater deal is still to be done. Child upbringing is not an easy task as parents of all cultures undeniably struggle to prepare their children for the inevitable complexities of life (Yorburg, 2002) and most of the time, child upbringing values are guided by parents' own experiences and how they were socialized, instinctive sense of right and wrong and their overall cultural beliefs (Hamner\& Turner, 2001).

\section{REFERENCES}

[1] Adorno, T., Frenkel-Brunswick, E., Levinson, D. and Sanford, N. (1950).The authoritarian personality. New York: Harper.

[2] African Ministers and Representatives of Ministers (2005).Moving Early Childhood Development Forward in Africa. Communique of the third African International Conference on Early Childhood Development. Accra, Ghana, May-June.

[3] Amin, M. E. (2005). Social science research: Conception, methodology and analysis. Kampala: Makerere University Press.

[4] Arnold, D. H., Zeljo, A., Doctor off, G. L. and Ortiz, C. (2008). Parent involvement in preschool: Predictors and the relation of involvement to preliteracy development. School Psychology Review, 37, 7490. 
Appraising Child Upbringing Values and its Influence on the Psycho-Social Development of Early Adolescents in Buea Sub-Division, South West Region, Cameroon

[5] Barsby, J. (2006). Fair trade: What cost a cup of coffee? The Traveler Msafiri, 57, 50-54.

[6] Bartz, K. W. and LeVine, E. S. (1978). Child rearing by black parents: A description and comparison to Anglo and Chicano parents. Journal of Marriage and the Family, 40, 709-719.

[7] Baumrind, D. (1971). Current patterns of parental authority. Developmental Psychology Monograph, 4(1, Pt.2).

[8] Baumrind, D. (1998). From "Ought" to "Is": A neo-Marxist perspective on the use and misuse of the culture construct. Human Development, 41, 145-165.

[9] Berk, L. E. and Winsler, A. (1995). Scaffolding children's learning: Vygotsky and early

[10] Bogdan, R. C. and Biklen, S. K. (2003).Qualitative research for education: An introduction to theory and methods. $4^{\text {th }}$ edition. Boston, Massachusetts: Allyn\& Bacon.

[11] Bogdan, R. C. and S. K. Biklen, (1992).Qualitative Research for Education. $2^{\text {nd }}$ Edition. Boston: Allyn and Bacon.

[12] Bradley, R. H. and Corwyn, R. F. (2002).Socioeconomic status and child development. Annu. Rev. Psychol, 53, 371-99.

[13] Bronfenbrenner, U. (1979). The ecology of human development. Cambridge, Massachusetts: Harvard University Press.

[14] Bullard, M., Carnes, J., Hofer, M., Polk, N. and Sneets, R. H. (1997).Stating Small: Teaching Tolerance in Preschool and the Early Grads. Maria, F., Gabrielle, L., Ting- Yi, O., Rosa, H. S., Glenda, V. and Elsie, W. (Editors). USA: Southern Poverty Law Centre.

[15] Buriel, R., Mercado, R., Rodriquez, J. and Chavez, J. M. (1991). Mexican American disciplinary practices and attitudes toward child maltreatment: A comparison of foreign and native-born mothers. Hispanic Journal of Behavioural Sciences, 13, 7894.

[16] Callaghan, L. (1998). Building on an African worldview. Early Childhood Matters, 89, 30-33.

[17] Carlson, J. M. and Iovini, J. (1985). The transmission of racial attitudes from fathers to sons: A study of Blacks and Whites. Adolescence, 20, 233-237.

[18] Christians, C. G. (2000). Ethics and politics in quantitative research: Handbook of Quantitative research. $2^{\text {nd }}$ ed. Edited by Denzin, N. K. and Lincoln, Y. S. Thousand Oaks, California: sage.

[19] Clifford, G. (1975). The Interpretation of Cultures. New York: Basic Books.

[20] Cohen, L., Manion, L. and Morrison, K. (2007).Research methods in education. $6^{\text {th }}$ Ed. Canada: Routledge.

[21] Crawford-Brown, C. (1999). The impact of parenting on conduct disorder in Jamaican male adolescents. Adolescence, 34, 417-436

[22] Creswell, J. W. (2009). Research Design, Qualitative, Quantitative and Mixed Methods Approaches. ${ }^{\text {rd }}$ Ed. London: Sage publications, Inc.

[23] Cunningham, C. E., Benness, B. B. and Siegel, L. S. (1988).Family functioning, time allocation and parental depression in the families of normal and ADDH children. Journal of Clinical Child Psychology, $17,169-177$.

[24] Daniels, H. (2001). Vygotsky and pedagogy. New York: Guilford Press.

[25] Davidson, P., Turiel, E. and Black, A. (1983). The effect of stimulus familiarity on the use of criteria and justifications in children's social reasoning. British Journal of Developmental Psychology, 1, 49-65.

[26] Davis, J. A. (1975). Communism, conformity, cohorts, and categories: American tolerance in 1954 and 1972-73. American Journal of Sociology, 81, 491-513.

[27] Dennis, J., Lindberg, L., McCrone, D. and Stiefbold, R. (1969).Political socialization to democratic orientations in four Western systems. Comparative Political Studies, I, 71-101.

[28] Denzin, N. K. and Lincoln, Y. S. (2005). Introduction: The discipline and practice of qualitative research. In Denzin, N. K. and Lincoln, Y.S. (Eds.) the SAGE Handbook of Qualitative Research. $3^{\text {rd }}$ Ed. Thousand Oaks, California: Sage.

[29] Dix, T., Ruble, D. N., Grusec, J. E. and Nixon, S. (1986). Social cognition in parents: Inferential and affective children of three age levels. Child Development, 57, 879-94.

[30] Ealsriwong, N. (2000), "Education for Peace", Mindnight Education. Retrieved on $21^{\text {st }}$ January 2018 from http://www.midnightuniv.org/midschool2000/ new page 7.htm

[31] Enright, R. D. and Lapsley, D. K. (1981).Judging others who hold opposite beliefs: The development of belief discrepancy reasoning. Child Development, 52, 1053-1063.

[32] Enright, R. D., Lapsley, D. K., Franklin, C. C. and Steuck, K. (1984).Longitudinal and cross-cultural validation of the belief-discrepancy reasoning construct. Developmental psychology, 20, 143-149.

[33] Fapounda, R. E. and Todaro, P. M. (1988). Family structure, implicit contracts, and the demand for children in Southern Nigeria: Population and Development Review, 14 (4): 571 - 594.

International Journal of History and Cultural Studies (IJHCS)

Page | 23 
Appraising Child Upbringing Values and its Influence on the Psycho-Social Development of Early Adolescents in Buea Sub-Division, South West Region, Cameroon

[34] Finazzo, A. D. (1997). All for the Children: Multicultural Essentials of Literature. New York: Delmar Publishers.

[35] Fraenkel, R. and Norman, E. (1990).How to design and evaluate research in education. Boston: McGraw Hill Publishing Co.

[36] Frankfurt, H. (1997). Equality and respect. Social Research, 64, 3-15.

[37] Frei, J. and Shaver, P. R. (2002). Respect in close relationships: Prototypes definition, self-report assessment, and initial correlates. Personal Relationships, 9, 121-139.

[38] French, P. A. (1979). The scope of morality. Minneapolis: University of Minnesota Press.

[39] Freud, S. (1930 and 1949). Civilization and its discontents. London: Hogarth.

[40] Garcia, M., Pence, A. and Evans, J. L. (Eds.). (2008). Africa's Future-Africa's Challenge: Early childhood care and development in sub-Saharan Africa (135-149). Washington, D. C.: World Bank.

[41] Gaskins, S. (1996). How Mayan parental theories come into play. In S. Harkness\& C. M. Super (Eds.), Parents' cultural belief systems: Their origins, expressions and consequences (345-363). New York: Guilford Publications.

[42] Gay, L. R. and Airasian, P. (2002). Educational research: Competences for analysis and application. $6^{\text {th }}$ edition. New Jersey: Prentice Hall.

[43] Hamner, T. J. and Turner, P. H. (2001).Parenting in contemporary society. Boston: Allyn\& Bacon.

[44] Harkness, S. and Super, C. M. (1992). Parental ethno theories in action. In Sigel, I. E., Mc GillicuddyDeLisi, A. V. and Goodnow J. J. (Eds.), Parental belief systems: The psychological consequences for children. $2^{\text {nd }}$ Ed. (373-391). Hillsdale, New Jersey: Lawrence Erlbaum Associates, Inc.

[45] Harkness, S. and Super, C. M. (Eds.). (1996). Parents cultural beliefs systems: Their origins, expressions and consequences. New York: The Guilford Press.

[46] Hatch, E. (1983).Culture and morality: The relativity of values in anthropology. New York: Columbia University Press.

[47] Helwig, C. C. (1995). Adolescents' and young adults' conceptions of civil liberties: Freedom of speech and religion. Child Development, 66, 152-166.

[48] Holden, G. W. and Edwards, L. A. (1989). Parental attitudes toward child rearing: Instruments, issues, and implications. Psychological Bulletin, 106, 29-58.

[49] Holloway, S. D., Gorman, K. S. and Fuller, B. (1988). Child-rearing beliefs within diverse structures: Mothers and day-care providers in Mexico. International Journal of Psychology, 23, 303-317.

[50] Hutson, A. C. (2002). Reforms and child development. Children and Welfare Reform, 12 (1), PrincetonBrookings.

[51] Jenkins, H. (1998). Introduction. In Jenkins, H. (ed.) The Children's Culture Reader. (pp. 1-37). New York: New York University Press.

[52] Johnson, B. J. and Onwuegbuzie, A. J. (2004). Mixed methods research: A research paradigm whose time has come. Educational Researcher, 33 (7), 14-26.

[53] Jones, R. S. (1980). Democratic values and pre-adult virtues: Tolerance, knowledge, and participation. Youth and Society, 12, 189-220.

[54] Julian, T. W., McKenry, P. C. and McKelvey, M. W. (1994). Cultural variations in parenting: Perceptions of Caucasian, African-American, Hispanic, and Asian-American parents. Family Relations, 43, 30-37.

[55] Kan, K. and Tsai, W.-D. (2005). Parenting practices and children's education outcomes. Economics of Education Review, 24(1), 29-43.

[56] Keeves, J. P. (Ed) (1997). Educational Research, Methodology, and Measurement: An International Handbook. Second Edition. London: Pergamon.

[57] Khadijah, R. M. Y. (2005). Child-rearing practices in rural poor Malay society: Nurturing an identity through Islamic values. In Asmah, H. O. and Morris, P. (Eds.), Religion \& Identity (120-133).

[58] Kincheloe, J. (1998). New Childhood. In Jenkins, H. (Ed.) The Children's Culture Reader (169-175). New York: New York University Press.

[59] Kohlberg, L. (1981). The philosophy of moral development moral stages and the idea of justice says on moral development. San Francisco: Harper \& Row.

[60] Kohlberg, L. (1984). The psychology of moral development: The nature and validity of moral stages. New York: Harper \& Row.

[61] Kohn, M. L. (1963). Social Class and Parent-Child Relationships: An Interpretation. The American Journal of Sociology, 68 (4), 471-480. 
Appraising Child Upbringing Values and its Influence on the Psycho-Social Development of Early Adolescents in Buea Sub-Division, South West Region, Cameroon

[62] Ladlia, K. (2006). Literature-Based Teaching Model for Enhancing Language Development of Preschool Student.Journal of YalaRajabhat University, 1 (1), 11-20.

[63] Lanyasunya, A. R. and Lesolayia, M. S. (2001). El-barta Child and Family Project.Working Papers in Early Childhood Development, No. 28. The Hague, The Netherlands: Bernard van Leer Foundation.

[64] Lawrence, D. (1976). Procedural norms and tolerance: A reassessment. American Political Science Review, 70, 80-100.

[65] Lawrence-Lightfoot, S. (1999).Respect: An exploration. Reading, Massachusetts: Perseus Books.

[66] LeVine, R. A. (1989). Cultural environments in child development.In Damon, W. (Ed.) Child development today and tomorrow (52-68). San Francisco: Josey-Bass.

[67] LeVine, R. A. (2004). Challenging expert knowledge: Findings from an African study of infant care and development. In Gielen, U. P. and Roopnarine, J. (Eds.), Childhood and adolescence: Cross-cultural perspectives and applications (149-165). Westport: Praeger.

[68] LeVine, R. A., Miller, P. M., Richman, A. L. and LeVine, S. (1996). Education and mother-infant interaction: A Mexican case study. In Harkness, S. and Super, C. M. (Eds.), Parents' cultural belief systems: Their origins, expressions and consequences (254-269). New York: Guilford Publications.

[69] Margalit, A. (1996). The decent society. Cambridge, Massachusetts: Harvard University Press.

[70] Masud, H. and Long, N. (Eds.) (2004). Handbook of parenting: Theory and research for practice. California: SAGE.

[71] Mazrui, A. A. (1986). The Africans. New York: Praeger.

[72] Mbiti, J. S. (1969). African Religions and Philosophy. Ibadan: Heinemann.

[73] McGillicuddy-De Lisi, A. V. and Subramanian, S. (1996). How do children develop knowledge? Beliefs of Tanzanian and American mothers. In Harkness, S. and Super, C. M. (Eds.), Parents' cultural belief systems (143-168). New York: Guilford.

[74] McMillan, R. and Schumacher, P. (2001).Research in education - a conceptual introduction. Pretoria: Longman.

[75] Mertler, C. A. and Charles, C. M. (2005).Introduction to Educational Research.5 ${ }^{\text {th }}$ edition. Boston, Massachusetts: Pearson Education.

[76] Miller, S. M. (1993). De politics of respect. Social Policy, 44-51.

[77] Miller, S. M. and Savoie, A. J. (2002).Respect and rights: Class, race, and gender today. New York: Rowman \&LittleGeld.

[78] Munday, R. (1979). When is a child a child? Alternative systems of classification. Journal of the Anthropological Society of Oxford, 10, 161-172.

[79] Ngaujah, D. E. (2003).An eco-cultural and social paradigm for understanding human development: A (West African) context. Graduate Seminar Paper (supervised by Dr. Dennis H. Dirks). La Mirada, California: Biola University.

[80] Nicoll, V. and Roberts, V., (1993) Taking a closer look at literature-based programs. Australia: Ambassder press.

[81] Nsamenang, A. B. (1992). Human development in cultural context: A third world perspective. Newbury Park, California: Sage Publications.

[82] Nsamenang, A. B. (1992a). Early childhood care and education in Cameroon. In Lamb, M. E. et al. (Eds.), Day care in context: Socio-cultural perspectives (419-439). Hillsdale, New Jersey: Erlbaum.

[83] Nsamenang, A. B. (1992b). Human development in cultural context: A third world perspective. Newbury Park, California: Sage.

[84] Nsamenang, A. B. (2001). Indigenous view on human development: A West African perspective. In Smelser, N. J. and Baltes, P. B... (Eds-in-Chief). International Encyclopaedia of the Social and Behavioural Sciences (7297-7299). London: Elsevier.

[85] Nsamenang, A. B. (2004). Cultures of human development and education: Challenge to growing up Africa. New York: Nova Publishers.

[86] Nsamenang, A. B. (2005). Educational development and knowledge flow: Local and global forces in human development in Africa. Higher Education Policy, 18, 275-288.

[87] Nsamenang, A. B. (2010). Childhoods within Africa's triple heritage. In Gaile S. C. and Diaz Soto, L. (Eds.), Childhoods: A Handbook (39-54). New York: Peter Lang. 
[88] Nsamenang, A. B. and Dawes, A. (1998). Developmental psychology as political psychology in subSaharan Africa: The challenge of Africanisation. Applied Psychology: An International Review, 47(1), 7387.

[89] Nsamenang, A. B. and Lamb, M. E. (1993).The acquisition of socio-cognitive competence by Nso children in the BamendaGrassfields of northwest Cameroon. International Journal of Behavioural Development, 16(3), 429-441.

[90] Nsamenang, A. B., Fai, P. J., Ngoran, G. N., Ngeh, M. Y., Forsuh, F. W. and Adzemye, E. W. (2008). Ethno theories of developmental learning in the Western Grassfields of Cameroon. In Dasen, P. R. and Akkari, A. (Eds.), Educational theories and practices from the "majority world" (49-70). New Delhi, India: Sage.

[91] Nucci, L. P. (1981). The Development of personal concepts: Domain Distinct from moral or societal concepts. Child development, 52:14-21.

[92] Nworgu, B. G. (1991). Educational Research: Basic issues and methodology. Ibadan: Wisdom Publishers.

[93] Ogbimi, G. E. and Alao, J. A. (1998).Developing sustainable day care services in rural communities of Nigeria. Early Child Development and Care, 145, 47-58.

[94] Pence, A. and Nsamenang, A. B. (2008).A case for early childhood development in sub-Sahara Africa. The Hague: Bernard van Leer Foundation.

[95] Pence, A. R. and Marfo, K. (Eds.).(2004). Capacity building for early childhood development in Africa [Special Issue]. International Journal of Educational Policy, Research and Practice, 5(3), 5-12.

[96] Piaget, J. (1952). The origins of intelligence in children. New York: International Universities Press.

[97] Prout, A. and James, A. (1990).A new paradigm for the sociology of childhood? Provenance, promise and problem. In James, A. and Prout, A. (Eds.), Constructing and reconstructing childhood: Contemporary issues in the sociological study of childhood (7-34). London, England: The Falmer Press.

[98] Rogoff, B. (2003). The cultural nature of human development. New York: Oxford University Press.

[99] Rooparine, B. and Brown, J. (Eds.) Caribbean families: Diversity among ethnic groups. (205-222). Greenwich: Ablex.

[100]Russell, L. D. (2005). Literature for Children.5th edition, New York: Pearson.

[101]Santman, D. (2006), our visions of Possibility for Literacy. Journal of Language Arts, 5 (83), 389-390.

[102]Serpell, R. (1979). How specific are perceptual skills? A cross-cultural study of pattern reproduction. British Journal of Psychology, 70, 365-380.

[103]Serpell, R. (1994). An African social ontogeny: Review of A. Bame Nsamenang (1992): Human development in cultural context: A Third World perspective. Sage Cross-cultural Research and Methodology Series. Cross-cultural Psychology Bulletin, 28(1), 17-21.

[104]Shey, P. and Tani, E, (2018).African Psychology: An Endogenous Life Span Development. (African Epistomology, Cosmology \& Ontology), 63-71. Buea: BENTI Ventures.

[105]Steinberg, L. and Silverberg, S. B. (1986).The vicissitudes of autonomy in early adolescence. Child Development, 57, 841-851.

[106]Szczepański, J. (1993). Środowiskowychowawcze. W: W. Pomykało (red.). Encyklopediapedagogiczna. Warszawa.

[107]Tamagola, T. A. (2006). RepublikKapling. Yogyakarta: Resist Book.

[108]Tande, K. E. (2011) Cultural Context of Development and the emerging practical intelligence of the Kpe child in Fako Division of Cameroon. PhD Thesis. Buea, Faculty of Education, University of Buea.

[109]Tani, E. L. and Tchombe S. M. (2016).Dynamics of indigenous Socialization Strategies and Emotion Regulation Adjustment among Nso Early Adolescents, North West Region of Cameroon. International Journal of Humanities, Social Sciences and Education, 3 (8), 86-124.

[110]Van Zalk, M. and Kerr, M. (2014).Developmental trajectories of prejudice and tolerance toward immigrants from early to late adolescence. Journal of Youth and Adolescence, 43, 1658-1671.

[111]Verma, G. and Beard, R. (1981). What is Educational Research. Londres: Gower.

[112]Weinberg, B. A. (2001). An incentive model of the effect of parental income on children. Journal of Political Economy, 109(2), 266-280.

[113]Weisner, T. S. (1997). Support for children and the African family crisis. In Weisner, T. S., Bradley, C. and Kilbride, C. P. (Eds.), African families and the crisis of social change (20-44). Westport: Bergin \& Garvey. 
Appraising Child Upbringing Values and its Influence on the Psycho-Social Development of Early Adolescents in Buea Sub-Division, South West Region, Cameroon

[114]Weisner, T. S. (2002). Ecocultural understanding of children's developmental pathways. Human Development, 174, 275-281.

Citation: Tani Emmanuel Lukong. Ph.D., Brentford AlemAtemkeng. "Appraising Child Upbringing Values and its Influence on the Psycho-Social Development of Early Adolescents in Buea Sub-Division, South West Region, Cameroon". International Journal of History and Cultural Studies (IJHCS). vol 6, no. 1, 2020, pp. 1127 doi: DOI: http://dx.doi.org/10.20431/2454-7654.0601003.

Copyright: (C) 2020 Authors. This is an open-access article distributed under the terms of the Creative Commons Attribution License, which permits unrestricted use, distribution, and reproduction in any medium, provided the original author and source are credited. 